\title{
Effect of post isometric relaxation technique in the treatment of mechanical neck pain
}

Mona H. El Laithy ${ }^{1 *}$ and Khaled Z. Fouda ${ }^{2}$

*Correspondence: mh_gamal@hotmail.com

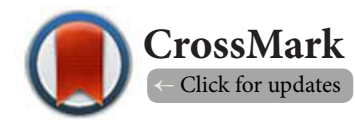

'Lecturer of physical therapy in the Physical Therapy for Musculoskeletal Disorders and its Surgery Department, Faculty of Physical Therapy, Cairo University, Egypt.

${ }^{2}$ Lecturer of Physical Therapy in Basic Science for Physical Therapy Department, Faculty of Physical Therapy, Cairo University, Egypt.

\begin{abstract}
Background and purpose: Neck pain is one of the most common musculoskeletal disorders in the general population which have large economic burden on the health care system. So, the purpose of the study was to investigate the effect of muscle energy technique in form of post isometric relaxation (PIR) with the traditional physical therapy treatment versus traditional physical therapy treatment alone on pain and range of motion (ROM) in patients with chronic mechanical neck pain (MNP).
\end{abstract}

Materials and methods: Thirty patients randomly assigned into two equal groups. Group A received a traditional physical therapy program while group B received the same program in addition to PIR technique instead of passive stretching. Neck pain and disability was measured using neck pain and disability scale while ROM of the cervical spine was measured by OB goniometer.

Results: There were significant decreases $(\mathrm{P}<0.05)$ in pain and there were significant increases $(\mathrm{P}<0.05)$ in ROM post treatment for both groups. However, there was significance differences $(\mathrm{P}<0.05)$ between both groups post treatment in the measurable variables.

Conclusion: Adding PIR technique to the conventional physical therapy treatment program of chronic MNP was more effective in reducing pain and functional disability and increasing cervical ROM than the traditional treatment program alone.

Keywords: Post isometric relaxation, Muscle energy technique, Neck pain, neck muscles

\section{Introdution}

Neck pain is one of the most common musculoskeletal disorders in the general population. Its prevalence ranges from $14.2 \%$ to $71 \%$ in the general population at some time in their lives. Neck pain was more prevalent among women and it is peaked in the middle aged people $[\mathbf{1 , 2}]$. The economic burden of neck pain condition is large on the health care system [3]. Neck pain was defined as the pain anywhere within the region bounded superiorly by superior nuchal line, inferiorly by an imaginary line through the tip of first thoracic spinous process and laterally by sagittal plane tangential to the lateral borders of the neck [4].

Mechanical neck pain (MNP) is a generalized neck and/or shoulder pain with mechanical characteristics, including symptoms produced by maintained neck postures, neck movement or by palpation of the cervical muscles [5]. The symptoms of
MNP have a postural or mechanical basis. The etiological factors are poorly understood and usually multifactorial including poor posture, anxiety, depression, muscle tightness, sport or occupational activities $[1,6]$.

The cervical spine is subject to stress and strain with daily activities such as sitting, lying in the supine or prone, speaking, rising, walking and turning. Most of the episodes of chronic neck pain are due to muscle strain and/or other tissue sprain [7]. The common muscles to be painful and tight in the cervical region are upper trapezius, levator scapulae, cervical erector spinae, scalene and sternocliedomastiod muscles. So that, regaining the normal length of the tight muscle should be emphasized initially during the program of treatment [8].

Muscle energy technique (MET) is an active muscle based treatment approaches that involves the voluntary contraction 
of a subject's muscle(s) in a precisely controlled direction, against a counterforce provided by the therapist. The MET may be used to decrease pain, stretch tight muscles and fascia, reduce muscle tonus, improve local circulation, strengthen weak musculature and mobilize joint restrictions. The MET is used for achieving tonus release in a muscle before stretching via introduction of an isometric contraction to the affected muscle producing post isometric relaxation [9].

Post isometric relaxation (PIR) is a MET used to relax and lengthen a hypertonic and shortened muscle. This gentle stretching technique is typically used on postural muscles. These muscles often become short and tight and can lead to muscle imbalances. This can limit range of motion and cause joint restrictions. Several muscles in the upper body fall under this category such as the upper trapezius, and levator scapulae. When these muscles become shortened they can restrict range of motion in the head, neck and shoulder and often become painful [10].

More recently, the treatment approaches for MNP evolved from a passive treatment technique towards more active treatment technique [11]. The MET is an advanced stretching techniques have been used in symptomatic as well as in asymptomatic population [11-19]. However, conflicting results are seen. There are a large number of treatment protocols for MNP are available. However, the most effective management remains an area of debate.

There is lack of high quality evidence to allow conclusions to be drawn about the effectiveness of MET for relieving MNP. So, the purpose of the study was to investigate the effect of MET in form of PIR with the traditional physical therapy treatment versus traditional physical therapy treatment alone on pain and range of motion in patients with chronic MNP.

\section{Meterials and Medthods Participants}

Thirty patients ( 18 females and 12 males) having chronic mechanical neck pain diagnosed by orthopedic physicians were recruited for the study from orthopedic outpatient clinics of Cairo University hospitals. Their age were ranged from (20-40) years and suffering from MNP for at least three months. Patients were excluded if they had any orthopedic or neurological condition or surgery in the cervical spine or shoulder.

The research design was randomized, single-blinded clinical trial. Randomization was performed by a statistician who was blinded to the study treatment and procedures' details. It was performed simply by adding a specific identification number for each patient. A SPSS program (version 20) was used to randomly assign the patients into two equal groups $(n=15)$. A written informed consent in accordance with the Declaration of Helsinki was signed by each participant before the beginning of the study. Confidentiality and anonymity of patient's data was considered and they have the right to withdraw from the study at any time.

\section{Outcome measures \\ Cervical range of motion}

Range of motion (ROM) of the cervical spine was measured by OB goniometer (Myrin: OB Rehab Co AN LIC-Company s17183 Solna, Sweden, T fin 08- 985370). The ROM was measured pre and post treatment in all directions. The goniometer was situated on the forehead to measure side bending, just above the ear to measure flexion and extension, and on the vertex to measure rotation. The $\mathrm{OB}$ goniometer is a reliable tool for measurement of the cervical ROM [20].

\section{Neck pain and disability}

Neck pain and disability was measured using neck pain and disability scale (NPAD) pre and post treatment. It consists of 20 items that measure the intensity and behavior of pain and its interference with vocational, recreational, social, functional as well as emotional aspects of living. Patients respond to each item by marking a $10 \mathrm{~cm}$ visual analogue scale (VAS). The maximum total score equal 100 points by dividing the total score 200 by 2 , that indicating maximum neck pain and disability. The less the total score, the more the improvement in neck pain and disability. The NPAD is a valid and reliable measure that deals specifically with neck pain [21].

\section{Procedures}

The purpose and procedures of the study were explained to all the patients through a demonstration session before the beginning of the study. Patients in group A received a traditional physical therapy program consisted of infra-red irradiation for 15 minutes, intermittent manual cervical traction from supine position (10 seconds pull, 5 seconds rest for 10 minutes), manual isometric strengthening exercises for cervical extension, flexion, bilateral side bending and bilateral rotation (resistance was about $50 \%$ of the patient's maximum strength, hold for 10 seconds, for 10 repetitions), passive stretching of the upper fibers of trapezius, sternocledomastoid, scalene and levator scapulae muscles (stretching was held for 30 seconds, and repeated 3 times).

Group $B$ received the same traditional physical therapy program in addition to PIR technique for the upper fibers of trapezius, levator scapulae, sternocledomastoid, scaleni and suboccipital muscles instead of passive stretching. PIR technique was applied from supine lying position with the head free from the plinth and held by the therapist's hand while the therapist was sitting on a stool at the head of the treatment table. The head was initially positioned so that the stretched muscle is in a lengthened position, the therapist applied isometric resistance to the action of the tight muscle and held for 7 seconds with gentle muscle contraction to avoid the risk of increasing the muscle tone, while breathing in with hold his breath during contraction, then the patient was asked to breathe out and relax for 3 seconds, then applied static stretching in the opposite direction for $30 \mathrm{sec}$. The procedure was repeated three times for each muscle bilaterally [22]. 
Post isometric relaxation was performed for upper fibers of trapezius, while the head and neck were flexed and side bent away from the side being treated to just short of restriction barrier with stabilization of the shoulder with one hand and the ipsilateral mastoid process with the other hand. Patient was asked to take the stabilized shoulder toward the ear, the ear toward the shoulder against resistance from both sides and to breathe in and hold his breath for 7 seconds. Then the patient was asked to breathe out, relax for 3 seconds and the shoulder was stretched caudally for 30 seconds [22].

For the levator scapulae, the therapist supported the neck in flexion, contralateral side bending and rotation with one hand. The other hand was placed on the patient's ipsilateral shoulder. The patient was asked to extend the head backward, slightly to the side from which it was turned, elevate the ipsilateral shoulder and to breathe in and hold his breath for 7 seconds. The therapist's other hand applied resistance against the shoulder elevation for 7 seconds and the patient was asked to breath out, relax for 3 seconds and the neck is taken to further flexion, side bending and rotation where it was maintained as the shoulder is depressed caudally with the patient's assistance for 30 seconds [22].

To perform PIR for the sternocleidomastoid muscle, the therapist placed one hand opposite the side of involvement muscle under the occipital ridge. The other hand is placed on the involved side of muscle so that the thumb is placed on the patient's forehead and the rest of that hand is rested on the side of the head. The head was moved into lateral flexion away from the side of involvement, rotation toward the side of involvement, and extension. The thumb of the therapist's hand on the involved side was placed on the forehead just over the patient's eye and. The patient pushed upward against the therapist's thumb on the forehead and looked up with taking a deep breath in for the contraction phase and hold his breath for 7 seconds, then the patient was asked to stop pushing and look down with breath out for 3 seconds. After the relaxation, the therapist stretched the muscle toward the floor by extension of the cervical spine for 30 seconds [22].

PIR was also applied for scalene muscle; the therapist placed one hand opposite the side of involvement muscle under the occipital ridge and the other hand that was placed on the side of involvement on the temporal bone. The head was moved into lateral flexion away from the side of involvement, rotation slightly from that side, and extension of the cervical spine. The patient was asked to press against this hand and to breathe in for the contraction phase and hold his breath for 7 seconds and then to stop pushing and to breathe out for the relaxation phase for 3 seconds. After that the therapist stretched the muscle into lateral flexion and extension for 30 seconds. The exercise was repeated 3 times on each side. In each time the starting position is just short of the new restriction range [22].

For the suboccipital muscles, the therapist's hand stabi- lized the $\mathrm{C}-2$ vertebra by grasping the transverse processes between the proximal portions of the thumb and index, and the other hand was under the occiput to take up the slack of the suboccipital muscles. The therapist pushed the head to flexion so that the chin moved toward the sternum and asked the patient to raise his eyes upward and to breathe in, hold his breath for for 7 seconds, and then the patient was asked to roll the eye downward, breathe out and relax for 3 seconds. The therapist took the head into further flexion ROM for 30 seconds [22].

The exercise was repeated 3 times in each time the starting position is just short of new restriction barrier for both muscles. All patients were treated for three sessions per week in alternative days for four weeks [22].

\section{Statistical analysis}

Data analysis was performed by statistical package for social studies (SPSS) (Version 22) for Windows. Descriptive statistics including the mean and standard deviation was used to describe general characteristics of subjects and outcome variables. Independent t test was used determine similarity between the groups at base line and demographic data. Two by two mixed design multivariate analysis of variance (MANOVA) with post hoc comparisons was used to compare all of the tested dependent variables within and between the two groups at pre-and post-treatment. The P-value $<0.05$ was taken as significant.

\section{Results}

As indicated by the independent $t$ test, there were no statistically significant differences $(P>0.05)$ between participants in both groups concerning age, weight, height and body mass index (BMI) as shown in Table 1.

Table 1. Demographic characteristics of participants.

\begin{tabular}{lllll}
\hline & Group A & Group B & \multicolumn{2}{c}{ Comparison } \\
\cline { 2 - 5 } & Mean \pm SD & Mean \pm SD & t-value & P-value \\
\hline Age (years) & $34.86 \pm 8.39$ & $32.46 \pm 6.54$ & 0.873 & 0.390 \\
Weight $(\mathrm{kg})$ & $83.33 \pm 6.84$ & $81.73 \pm 4.99$ & 0.732 & 0.470 \\
Height $(\mathrm{cm})$ & $168.4 \pm 4.68$ & $167.6 \pm 6.08$ & 0.404 & 0.690 \\
Body mass index & $29.38 \pm 4.96$ & $29.09 \pm 5.88$ & 0.146 & 0.885 \\
\hline
\end{tabular}

SD: Standard deviation, $\mathrm{P}>0.05$ Non significance

Independent t-test revealed that there was no significance difference $(P>0.05)$ between both groups pre-treatment in the measurable outcomes as shown in Table 2, while statistical analysis using MANOVA revealed that there was significant difference $(P<0.05)$ between the pre-treatment values and post-treatment values regarding to the measured outcomes for both groups. Multiple pair wise comparison tests (Post hoc tests) revealed that there were significant decreases $(P<0.05)$ in pain and disability (measured by NPAD scale) in the post 
treatment condition compared with the pre-treatment one in both groups. However, there were significant increases $(\mathrm{P}<0.05)$ in ROM for (neck flexion, extension, right bending, left bending, right rotation and left rotation) in the post treatment condition compared with the pre-treatment one in both groups as shown in Tables $\mathbf{3}$ and $\mathbf{4}$.

Also, post hoc test revealed that there were significant differences $(P<0.05)$ between both groups post treatment in the measurable variables as shown in Table 5.

\section{Discussion}

The current study was designed to investigate the effect of MET in form of PIR with the traditional physical therapy treatment versus traditional physical therapy treatment alone on pain and range of motion in patients with chronic MNP. The results of the current study revealed that adding MET in the form of PIR to a traditional physical therapy program (infra-red radiation, traction and isometric strengthening) significantly improved the effect of treatment on pain, cervical ROM and

Table 2. Comparing mean values for the measured outcomes pre-treatment for both groups.

\begin{tabular}{lllll}
\hline & \multicolumn{2}{l}{$\begin{array}{l}\text { Group A } \\
\text { Variables }\end{array}$} & Group B & \multicolumn{2}{l}{ Comparison } \\
Pre-treatment & \multicolumn{2}{l}{ t-value } & P value \\
\hline NPAD & $54.86 \pm 11.03$ & $57.46 \pm 16.93$ & 0.575 & 0.568 \\
ROM of neck flexion & $60.53 \pm 7.34$ & $60.46 \pm 5.92$ & 0.033 & 0.973 \\
ROM of neck extension & $52.06 \pm 5.98$ & $49.73 \pm 5.66$ & 1.266 & 0.213 \\
ROM of right bending & $30.13 \pm 3.92$ & $28.40 \pm 3.06$ & 1.556 & 0.128 \\
ROM of left bending & $29.93 \pm 4.07$ & $28.73 \pm 2.91$ & 1.073 & 0.291 \\
ROM of right rotation & $63.60 \pm 7.66$ & $65.86 \pm 8.99$ & 0.855 & 0.397 \\
ROM of left rotation & $62.26 \pm 6.69$ & $61.86 \pm 6.37$ & 0.193 & 0.847 \\
\hline
\end{tabular}

$\mathrm{P}>0.05$ Non significance

Table 3. Post hoc test of the measurable variables for group A.

\begin{tabular}{lllll}
\hline & Group A & & P value & $\begin{array}{c}\text { Percentage of } \\
\text { improvement }\end{array}$ \\
\hline Variables & Pre-treatment & Post-treatment & & \\
\hline NPAD & $54.86 \pm 11.03$ & $40.73 \pm 10.68$ & $0.001^{*}$ & $25.75 \%$ \\
ROM of neck flexion & $60.53 \pm 7.34$ & $67.40 \pm 7.72$ & $0.001^{*}$ & $11.34 \%$ \\
ROM of neck extension & $52.06 \pm 5.98$ & $58.80 \pm 5.99$ & $0.001^{*}$ & $12.94 \%$ \\
ROM of right bending & $30.13 \pm 3.92$ & $36.01 \pm 3.85$ & $0.001^{*}$ & $19.51 \%$ \\
ROM of left bending & $29.93 \pm 4.07$ & $35.80 \pm 4.25$ & $0.001^{*}$ & $19.61 \%$ \\
ROM of right rotation & $63.60 \pm 7.66$ & $69.93 \pm 8.19$ & $0.001^{*}$ & $9.95 \%$ \\
ROM of left rotation & $62.26 \pm 6.69$ & $69.13 \pm 6.85$ & $0.001^{*}$ & $11.03 \%$ \\
\hline
\end{tabular}

$\mathrm{P}<0.05$ Non significance

Table 4. Post hoc test of the measurable variables for group $B$.

\begin{tabular}{lllll}
\hline & Group B & & P value & $\begin{array}{c}\text { Percentage of } \\
\text { improvement }\end{array}$ \\
\hline Variables & Pre-treatment & Post-treatment & & \\
\hline NPAD & $57.46 \pm 16.93$ & $30.60 \pm 14.81$ & $0.001^{*}$ & $46.74 \%$ \\
ROM of neck flexion & $60.46 \pm 5.92$ & $75.06 \pm 7.24$ & $0.001^{*}$ & $24.14 \%$ \\
ROM of neck extension & $49.73 \pm 5.66$ & $63.26 \pm 4.47$ & $0.001^{*}$ & $27.20 \%$ \\
ROM of right bending & $28.40 \pm 3.06$ & $38.93 \pm 2.76$ & $0.001^{*}$ & $37.07 \%$ \\
ROM of left bending & $28.73 \pm 2.91$ & $40.06 \pm 2.18$ & $0.001^{*}$ & $39.43 \%$ \\
ROM of right rotation & $65.86 \pm 8.99$ & $77.20 \pm 6.30$ & $0.001^{*}$ & $17.21 \%$ \\
ROM of left rotation & $61.86 \pm 6.37$ & $74.66 \pm 6.44$ & $0.001^{*}$ & $20.69 \%$ \\
\hline P 0.05 Non significance & & & &
\end{tabular}

$\mathrm{P}<0.05$ Non significance 
El-Laithy et al, Physical Therapy and Rehabilitation 2018,

http://www.hoajonline.com/journals/pdf/2055-2386-5-20.pdf

Table 5. Comparing of the mean values of both groups post-treatment.

\begin{tabular}{llll}
\hline & Group A & Group B & P value \\
\hline Variables & \multicolumn{3}{l}{ Post-treatment } \\
\hline NPAD & $40.73 \pm 10.68$ & $30.60 \pm 14.81$ & $0.040^{*}$ \\
ROM of neck flexion & $67.40 \pm 7.72$ & $75.06 \pm 7.24$ & $0.009^{*}$ \\
ROM of neck extension & $58.80 \pm 5.99$ & $63.26 \pm 4.47$ & $0.028^{*}$ \\
ROM of right bending & $36.01 \pm 3.85$ & $38.93 \pm 2.76$ & $0.024^{*}$ \\
ROM of left bending & $35.80 \pm 4.25$ & $40.06 \pm 2.18$ & $0.001^{*}$ \\
ROM of right rotation & $69.93 \pm 8.19$ & $77.20 \pm 6.30$ & $0.011^{*}$ \\
ROM of left rotation & $69.13 \pm 6.85$ & $74.66 \pm 6.44$ & $0.031^{*}$ \\
\hline
\end{tabular}

${ }^{\star} \mathrm{P}<0.05$ Significance

function in patients with chronic MNP. The PIR with traditional physical therapy program were more effective than traditional physical therapy program alone in reducing pain and disability and in increasing cervical ROM.

The results of present study were in agreement with other previous studies that showed that the PIR has a significant effect in reduction of pain and increasing of ROM in the neck area or in other areas of the body $[10-17,19,23]$. However, the results of the current study showed increase in all ranges of neck motion which is superior to other studies conducted on neck pain $[10,23]$. This may be attributed to the number of muscles on which PIR was applied in this study. Within the available literatures and for our knowledge this is the first study which investigated the effect of PIR with strengthening exercise as a part of traditional physical therapy program for patients with chronic MNP.

The physiological principles on which MET is based on are PIR and reciprocal inhibition. PIR refers to the assumed effect of reduced tone experienced by a muscle, or group of muscles, after brief periods following an isometric contraction. Pain reduction following PIR could be attributed to the inhibitory Golgi tendon reflex, activated during isometric contraction that leads to reflex relaxation of muscle [22]. Also activation of muscle and joint mechanoreceptors leads to sympathoexcitation evoked by somatic efferents and localized activation of periaqueductal gray matter that plays a role in descending modulation of pain [24].

Moreover, the level of pain could be decreased by isometric exercises due to increase endorphins that occur usually after training and better neuromuscular control. The strong muscle contractions happen during isometric exercise which activates muscles stretch receptors. These afferent from these receptors cause endogenous opoids to be released and also cause the release of beta endorphins from the Pituitary gland, these secretions may cause decrease pain [25].

Increased ROM following application of PIR could be explained on the basis of physiological mechanisms behind the changes in muscle extensibility which leads to an increase in muscle length by a combination of creep and plastic change in the connective tissue [26]. Increasing in muscle extensibility may be also attributed to neurophysiological factors (such as changes in the stretch tolerance) and mechanical factors (such as viscoelastic changes in the connective tissue elements of the muscle) [27].

The inhibitory effect of Golgi tendon reflex which activated during isometric contraction of muscle leading to reflex relaxation of the muscle and reduction in muscle spasm and tightness. So, the possible explanation of the increased in ROM relies mainly on the effect of autogenic inhibition $[\mathbf{2 8 , 2 9 ]}$.

\section{Limitations}

This study was limited by the small sample size and absence of long term evaluation of the outcomes. Other studies with larger sample sizes and longer duration are recommended.

\section{Conclusion}

Adding muscle energy technique in the form of PIR to the conventional physical therapy treatment program of chronic MNP was more effective in reducing pain and functional disability and increasing cervical ROM than the traditional treatment program alone.

\section{Competing interests}

The authors declare that they have no competing interests.

\section{Authors' contributions}

\begin{tabular}{|l|c|c|}
\hline Authors' contributions & MHE & KZF \\
\hline Research concept and design & $\checkmark$ & -- \\
\hline Collection and/or assembly of data & $\checkmark$ & $\checkmark$ \\
\hline Data analysis and interpretation & -- & $\checkmark$ \\
\hline Writing the article & $\checkmark$ & $\checkmark$ \\
\hline Critical revision of the article & $\checkmark$ & $\checkmark$ \\
\hline Final approval of article & $\checkmark$ & -- \\
\hline Statistical analysis & -- & $\checkmark$ \\
\hline
\end{tabular}

\section{Acknowledgment}

The researchers are indebted to Cairo University, Egypt, Faculty of Physical Therapy for their permission to commencement the study and to the participants.

\section{Publication history}

Editor: Gordon John Alderink, Grand Valley State University, USA. Received: 06-Oct-2018 Final Revised: 17-Nov-2018

Accepted: 21-Nov-2018 Published: 05-Dec-2018

\section{References}

1. Binder Al. Cervical spondylosis and neck pain. BMJ. 2007; 334:527-31. | Article | PubMed Abstract | PubMed FullText

2. Fejer R, Kyvik KO and Hartvigsen J. The prevalence of neck pain in the world population: a systematic critical review of the literature. Eur Spine J. 2006; 15:834-48. | Article | PubMed Abstract | PubMed FullText

3. Nagrale AV, Glynn P, Joshi A and Ramteke G. The efficacy of an integrated neuromuscular inhibition technique on upper trapezius trigger points in subjects with non-specific neck pain: a randomized controlled trial. J Man Manip Ther. 2010; 18:37-43. | Article | PubMed Abstract | PubMed FullText 
El-Laithy et al, Physical Therapy and Rehabilitation 2018,

4. Misailidou V, Malliou P, Beneka A, Karagiannidis A and Godolias G Assessment of patients with neck pain: a review of definitions, selection criteria, and measurement tools. J Chiropr Med. 2010; 9:49-59. | Article | PubMed Abstract | PubMed FullText

5. Fernandez-de-las-Penas $C$, Palomeque-del-Cerro L, Rodriguez-Blanco $\mathrm{C}$, Gomez-Conesa A and Miangolarra-Page JC. Changes in neck pain and active range of motion after a single thoracic spine manipulation in subjects presenting with mechanical neck pain: a case series. $J$ Manipulative Physiol Ther. 2007; 30:312-20. | Article I PubMed

6. Cote P, Cassidy JD, Carroll $\mathrm{LJ}$ and Kristman V. The annual incidence and course of neck pain in the general population: a population-based cohort study. Pain. 2004; 112:267-73. | Article | PubMed

7. Cote $P$, Cassidy JD and Carroll L. The factors associated with neck pain and its related disability in the Saskatchewan population. Spine (Phila Pa 1976). 2000; 25:1109-17. I Article | PubMed

8. Andersen LL, Hansen K, Mortensen OS and Zebis MK. Prevalence and anatomical location of muscle tenderness in adults with nonspecific neck/shoulder pain. BMC Musculoskelet Disord. 2011; 12:169. | Article | PubMed Abstract | PubMed FullText

9. Fryer $\mathrm{G}$ and Ruszkowski W. The influence of contraction duration in muscle energy technique applied to the atlanto-axial joint. Journal of Osteopathic Medicine. 2004; 7:79-84.

10. Gupta S, Jaiswal P and Chhabra D. A comparative study between postisometric relaxation and isometric exercises in non-specific neck pain. Journal of exercise science and physiotherapy. 2008; 4:88-94.

11. Yadav $\mathrm{H}$ and Goyal $\mathrm{M}$. Efficacy of muscle energy technique and deep neck flexors training in mechanical neck pain- A randomized clinical trial. International Journal of Therapies and Rehabilitation Research. 2015; 4:52-66

12. Joshi1 $R$ and Rathi $M$. Effect of muscle energy technique versus positional release technique on pain and functions in patients with trapezitis. A comparative study. International Journal of Science and Research. 2017; 6:2113-2115

13. Phadke A, Bedekar N, Shyam A and Sancheti P. Effect of muscle energy technique and static stretching on pain and functional disability in patients with mechanical neck pain: A randomized controlled trial. Hong Kong Physiotherapy Journal. 2016; 35:5-11. | Article

14. Kumari1 C, Sarkar B and Banerjee D et al. Efficacy of muscle energy technique as compared to proprioceptive neuromuscular facilitation technique in chronic mechanical neck pain: A randomized controlled trial. International Journal of Health Sciences \& Research. 2016: 6:152161. | Article

15. Mazumdar J and Shriwas JK. A comparison between mulligan traction straight leg raise technique versus muscle energy technique on hamstring tightness in asymptomatic male. Int J Physiother Res. 2014; 2:412-417. I Pdf

16. Prashant N, Anand $\mathrm{H}$ and Subhash K. Comparison of muscle energy technique and positional release therapy in acute low back pain RCT. Ind J Physiother Occup Ther. 2010; 4:32-36. | Article

17. Hashim A, Mohd M and Shveta K. Effect of muscle energy technique and static stretching on hamstring flexibility in healthy male subjects. Ind $J$ Physiother Occup Ther. 2010; 4:32-36.

18. Shadmehr A, Hadian MR, Naiemi SS and Jalaie S. Hamstring flexibility in young women following passive stretch and muscle energy technique. $J$ Back Musculoskelet Rehabil. 2009; 22:143-8. | Article I PubMed

19. Mahajan R, Kataria $C$ and Bansal K. Comparative effectiveness of muscle energy technique and static stretching for treatment of sub-acute mechanical neck pain. Int J Health Rehabil Sci. 2012; 1:16-24. | Article

20. Balogun J, Abereoje O, Olaogun M and Obajuluwa V. Inter and intratester reliability of measuring neck motions with tape measure and Myrin gravity reference goniometer. Journal of Orthopedic and Sports Physical Therapy. 1989; 1:248-253. | Article

21. Wheeler AH, Goolkasian P, Baird AC and Darden BV, 2nd. Development of the Neck Pain and Disability Scale. Item analysis, face, and criterionrelated validity. Spine (Phila Pa 1976). 1999; 24:1290-4. | Article | PubMed

22. Chaitow L. An introduction to muscle energy techniques: Muscle energy technique. 3rd. ed. Churchill Livingstone, 2006.

23. Haritha $P$, Shanthi $C$ and Madhavi K. Efficacy of post isometric relaxation versus static stretching in subjects with chronic non specific neck pain. International Journal of Physiotherapy. 2015; 2:1097-1102.

24. Fryer $G$ and Ruszkowski W. The influence of contraction duration in muscle energy technique applied to the atlanto-axial joint. J Osteopath Med. 2004; 7:79-84. I Article

25. Burns DK and Wells MR. Gross range of motion in the cervical spine: the effects of osteopathic muscle energy technique in asymptomatic subjects. J Am Osteopath Assoc. 2006; 106:137-42. | Article I PubMed

26. Clark RA. Hamstring injuries: risk assessment and injury prevention. Ann Acad Med Singapore. 2008; 37:341-6. | Pdf | PubMed

27. Freyer G. Muscle Energy concepts - a need for change. J Osteopath Med. 2003; 3:54-59.

28. Ballantyne F, Freyer $G$ and McLaughlin P. The effect of muscle energy technique on hamstring extensibility: the mechanism of altered flexibility. J Osteopath Med. 2003; 6:59-63. | Article

29. Frontera WR. Rehabilitation of sports injuries: Scientific basis. 1st ed Oxford: Wiley Blackwell. 2003; 232-257.

Citation:

El-Laithy $\mathrm{MH}$ and Fouda KZ. Effect of post isometric relaxation technique in the treatment of mechanical neck pain. Phys Ther Rehabil. 2018; 5:20. http://dx.doi.org/10.7243/2055-2386-5-20 